\title{
Organization of Tropical East Pacific Convection (OTREC): The importance of field projects and international collaboration
}

\author{
Zeljka Fuchs-Stone \\ Climate and Water Consortium \\ at New Mexico Tech (NMT)
}

Organization of Tropical East Pacific Convection (OTREC 2019) is a collaborative international scientific project, funded by the US National Science Foundation with 5.4 million dollars, to study the weather in the tropical eastern Pacific and western Caribbean.

How do we justify the cost of a field project?

The weather forecasts, that we depend on for many aspects of modern life, and the climate models, that tell us what the future brings, are made possible by computer models that simulate the behavior of the atmosphere. The models are not perfect though. They are based on our understanding of the physics and on observations/measurements that we have. We need observations to initialize and evaluate models.

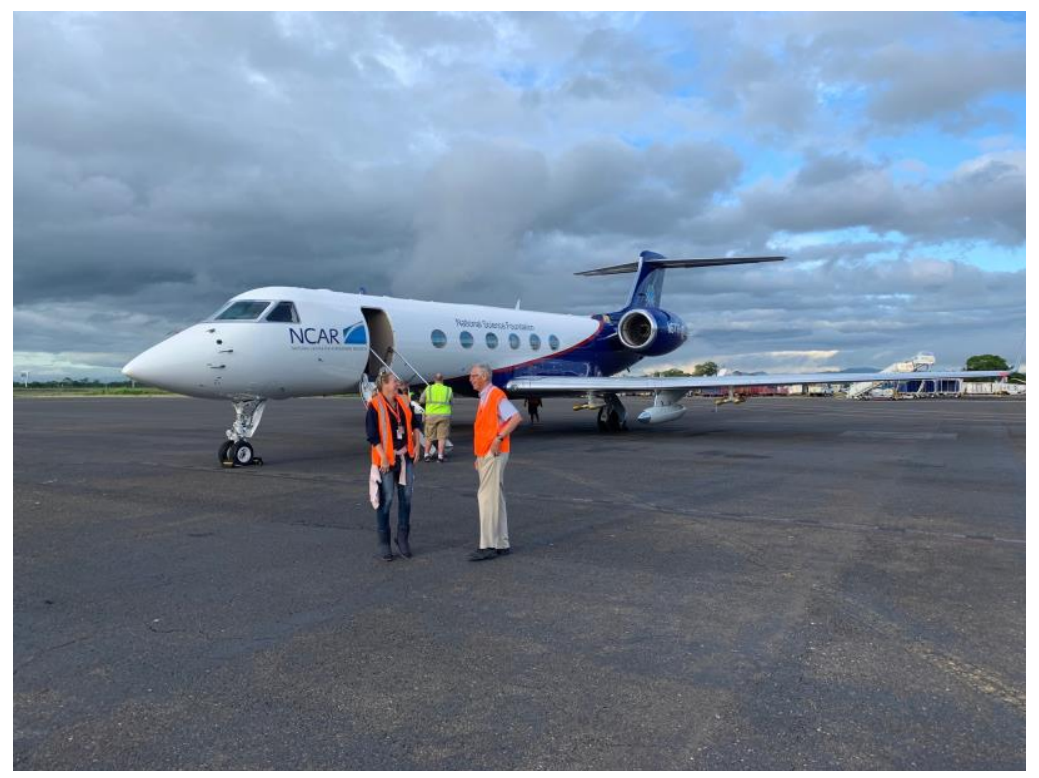


Weather forecast in the tropics is particularly challenging. Most of the tropics is covered by ocean, so that in situ observations are sparse. Also, weather in the tropics is strongly controlled by deep convective cloud systems - complexes of thunderstorms whose clouds reach high up into the atmosphere, that produce heavy rain, that steer the winds on large scales, and that sometimes organize into hurricanes. Our understanding of these deep convective systems remains quite incomplete despite decades of study, and models still struggle to represent them well. Basic questions are: why does convection develop at particular places and times and not others? Why does it sometimes develop and sometimes not, even when conditions seem the same? OTREC tries to answer these questions by gathering an impressive data set that scientists all over the world will use for decades to come. This will improve the models and give more accurate forecasts and climate predictions from which our economy (agriculture, ranching, forestry, renewable energy, travel, water management...) and our health will benefit a lot.

The area of the OTREC study was chosen because of its unique climate. The Eastern Pacific has a very strong meridional sea surface temperature gradient with the coldest temperatures on the equator. In contrast, Southwest Caribbean has uniform sea surface temperature. Together those two regions represent very diverse environments and a perfect place to study convection.

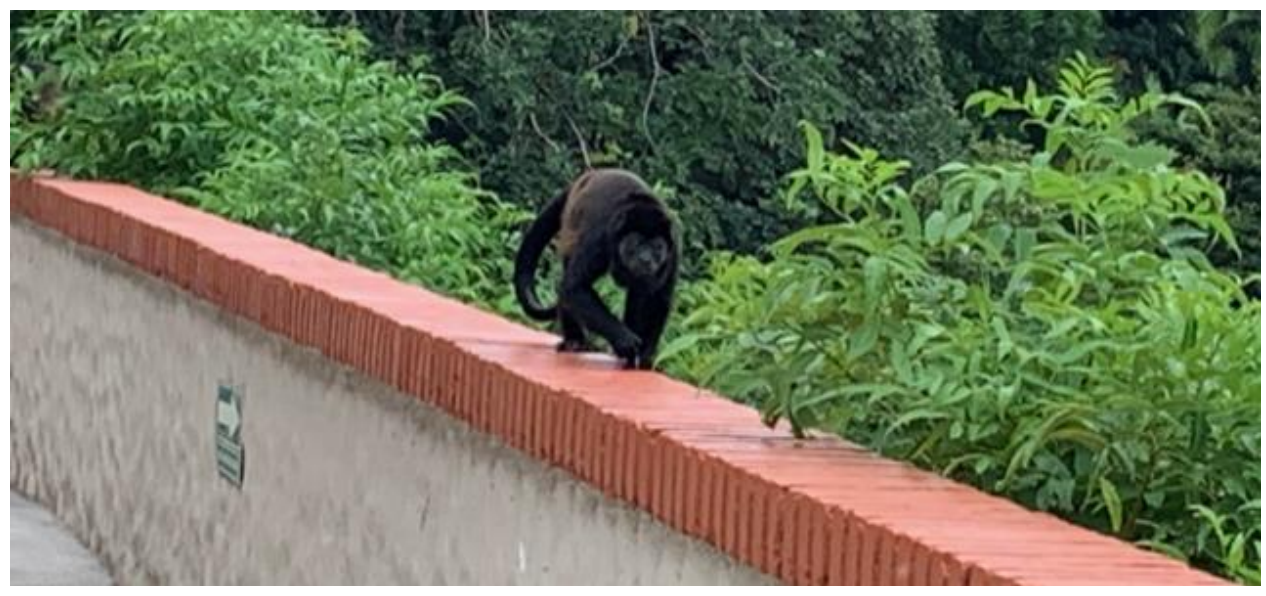

The field phase of OTREC took place from August 5 to October 3, 2019. Dozens of scientists and students from the USA, together with colleagues and students from Costa Rica, UK, Colombia and Mexico flew onboard the NCAR/NSF Gulfstream V (G-V) aircraft gathering data. We performed 22 research flights which amounted to 127 research hours. 648 dropsondes (instruments that measure temperature, humidity, wind, etc., all the way from the plane to the ocean; similar to weather balloons - radiosondes, but they fall down with a parachute instead of rising up with a balloon) were deployed. We had NCAR's downward-pointing W-band radar (Hiaper Cloud Radar), which can see rain-bearing clouds onboard the GV. Radiosondes were launched from the ground from locations in Costa Rica (Limón and San Jose) and Colombia (Nuquí). Intensified radiosonde launching was done all over Colombia at their regular sites. Weather and global positioning 
system column water vapor stations were gathering data all over Costa Rica and Colombia. Rainfall samples were collected in Costa Rica and Colombia.

How does a project like this come together? When all is said and done, the best I can say is that you need to sleep/eat/breathe only for the project, you need an amazing team and some luck along the way! We had amazing support from NCAR as well as from our international collaborators. Importing expendables such as dropsondes (they fall into the ocean and you cannot export them back out of the country) is always a challenge no matter how much you prepare everything in advance. Without the help from our colleagues from the University of Costa Rica, we would have paid more and it would have taken longer (a similar thing happened for field project EPIC when support from UNAM was crucial). The ground operation would have been impossible to pull off without our colleagues from Costa Rica and Colombia (University of Bogota and Medellin). Hosting an open house (a day when the public comes to see the plane and all the instruments) as a part of outreach would have been impossible without help from our hosts as well as numerous undergraduate and graduate students from Mexico, Costa Rica and Colombia as well as US. It takes a village certainly applies to field projects! I was even told once that we needed a school bus!

On most days we had about 20 people in a science team. We stayed at Condovac which is a beautiful family oriented condo style resort. We were so warmly welcomed that every week the hotel organized a party with barbecue and dancing for us. We had a kitchen in our condos which is very important if you are living away from home for 2 months. The grocery stores were nearby and we had enough rent-a-cars to pull the transportation off without the use of the school bus.

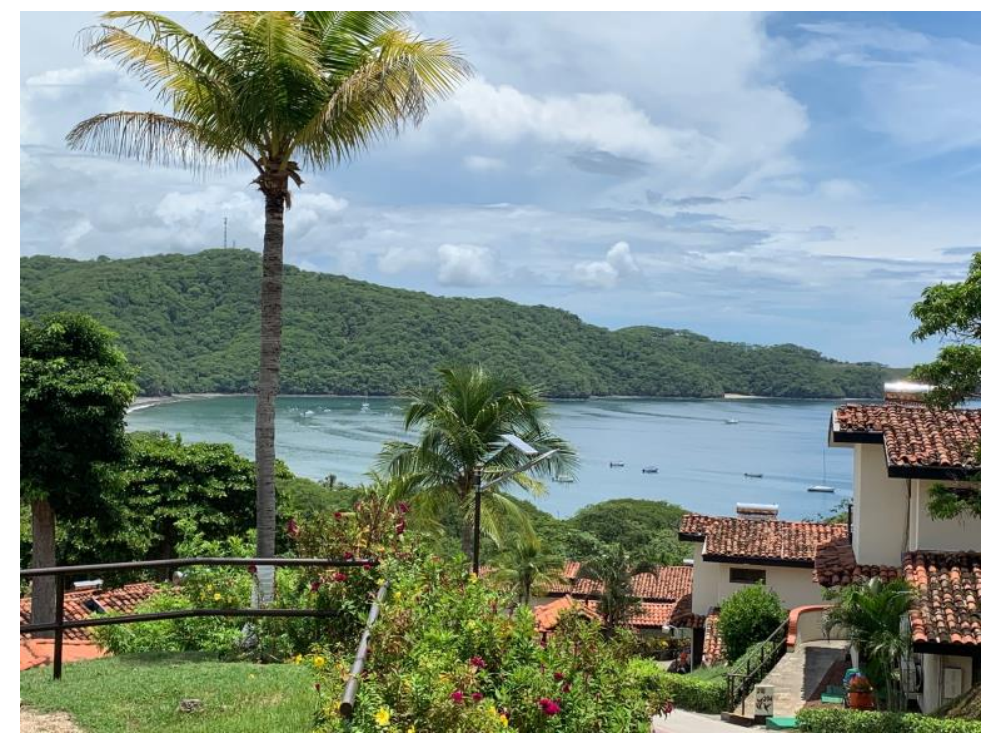


On flight days I got up at 3 am. Dave Raymond and I alternated as mission scientists, but we always talked around 3:30 am to discuss the latest satellite images. Unlike many projects, the flight patterns were predefined in OTREC. We knew that we wanted to fly in "B1" pattern on a given day, followed by the "B2" pattern the very next day. B1 pattern meant that we flew in Eastern Pacific off the coast of Colombia (our colleagues stationed in Nuquí doing intensified launches on that day would wave at us; they saw us, we didn't see them), then crossed Panama and flew in Southwest Caribbean region. The next day we would fly further west in Eastern Pacific ITCZ region. The reasoning behind that was that it takes a day for possible easterly waves that formed off the coast of Colombia or are crossing from Southwest Caribbean to reach our B2 box. But how to figure out when to start B1-B2 flights? Do we depend on weather forecast that, as already mentioned, is not very accurate in the tropics? Do we always try to fly in some convection or storms? Dave and I thought otherwise. We decided to flip a coin to randomly decide when to fly. Nobody believed us that we could pull it off! Scientists, by design, always want to fly into storms! But, the goal of OTREC was to collect the data set of all different forms of convection including the cases of no convection. We think that only that way will we have a complete picture of what is really happening in the troposphere. So, our 3:30 am discussion was not about where to fly, but about how hard it will be to maintain the 1 by 1 degree grid for dropsondes. Even though people call us the storm trackers, when the pilot says that we cannot fly in a certain area because of lightning and convection, we must listen. Then it is up to the mission scientist to decide how to go around lightning while still keeping the grid somewhat regular. Another reason to avoid flying through deep convection is that deploying dropsondes in those conditions might result in loss of data.

It is 3:45 now and Dave or I with a car full of colleagues and students head out of Condovac towards the Liberia airport. The howler monkeys are seeing us off. Depending on road conditions and weather conditions (fog, heavy rain), we arrive to the airport at 4:30 am. We have an amazing relationship with the airport people and someone comes to pick us up in a van. We drive for 2 minutes to the plane avoiding security etc. Take off time is planned for a bit after 6 am as the airport opens at 6 . The NCAR crew is all there, making sure that the plane is ready to go. The pilots have already filed the flight plan; all we need is a 6 am clearance. We take lots of pictures, show the students where the radar is, do the safety briefing on site, start up the computers onboard. I stare at the satellite images some more. At 5:30 the doors close. The NCAR crew is seeing us off, making sure all systems are a go. It is 6:10 and we are in the air within minutes. G$\mathrm{V}$ has huge windows that warm up as we take off. Breakfast time during the ferry towards the flight area and then the real work begins. For our field project it was crucial to be on top of things ahead of time as any significant change in course had to be discussed with pilots at least half an hour ahead of time. We either had headphones on or we walked to the pilot cabin. Five hours later we ferry back home, exhausted, but most of the time filled with joy and adrenaline, anxious to get back to our hotel, have lunch and debrief with the crew on the ground. Next is writing a mission report as during the flight we keep a detailed log. In the late afternoon most of us went swimming in the ocean before dinner and then finally off to bed! 

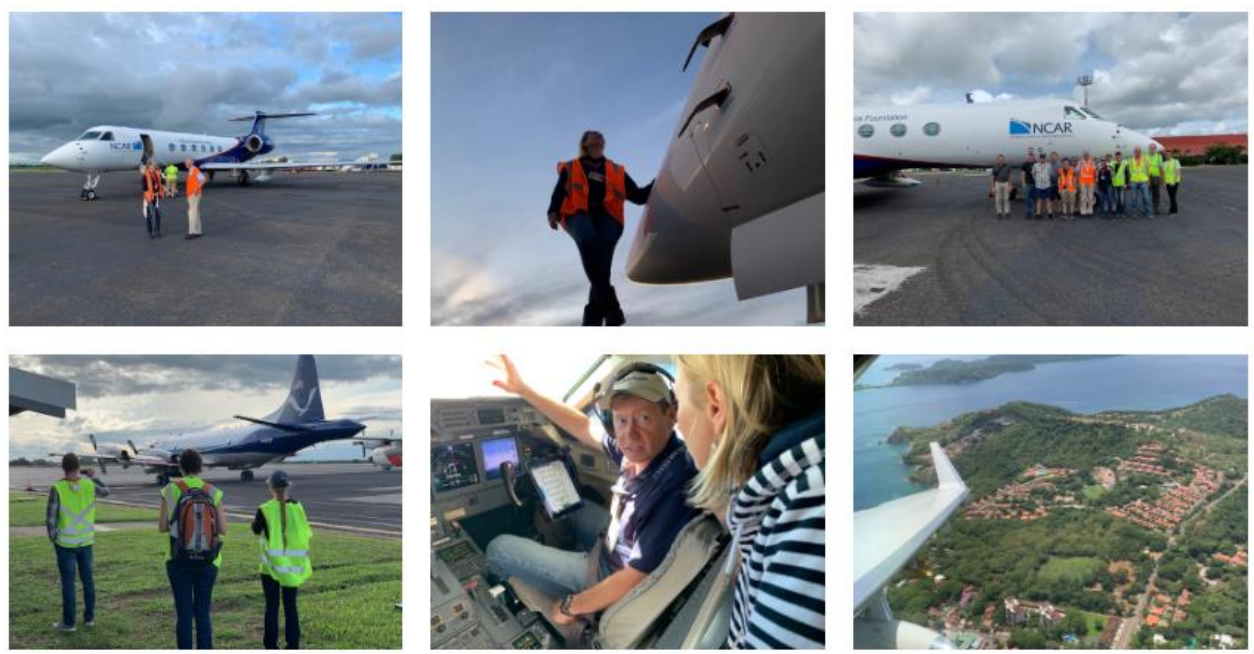

Field projects are hard to pull off because there are so many unexpected things that can happen. Some of those are extraordinary such as "hurricane hunters" from NOAA joining us with their aircraft P-3 and us flying jointly into developing tropical storm Ivo! You need extraordinary team work where everyone gives their very best! Science does not know of borders and it really showed during OTREC. We ALL lived for OTREC! Field projects are also an excellent place for students to bond with researchers and professors and I would advise every student to try and participate in one.

It has been my great privilege to work with so many great scientists and their students. Thank you OTREC, thank you US, Costa Rica, Colombia, Mexico and UK!

The core group of US investigators in OTREC consists of scientists from Harvard University, University of Wisconsin, National Oceanic and Atmospheric Administration, Colorado State University, University of Washington, Columbia University and New Mexico Tech. The international collaborators are from Mexico, Costa Rica, Colombia and United Kingdom. The project is being led by physicists Zeljka Fuchs-Stone and David J. Raymond from New Mexico Tech. 